\title{
Development Of An Ultra-Lightweight Thin Film Polymer Modified Concrete Material
}

\author{
Deon Kruger $^{a}$, Michael van der Westhuizen ${ }^{b}$ \\ Department of Civil Engineering Science University of Johannesburg Aucklandpark, South Africa \\ adkruger@uj.ac.za, ${ }^{b}$ mvderwest@gmail.com
}

Keywords: lightweight aggregates, lightweight concrete, polymer modified concrete, thin film concrete

\begin{abstract}
Certain construction situations call for the use of ultra-lightweight concrete materials. The properties of such materials allow for the utilisation of concrete in weight critical applications, for example precast elements, roofing panels, flooring and cladding of structures. The weight saving benefits of lightweight concrete are evident, yet a trade-off in the strength and durability characteristics of the concrete are made. This paper sets out to develop an ultra-lightweight thin filmed polymer modified concrete material for such applications. This material may incorporate specialised aggregates and admixtures to meet performance requirements but the effects of these on the performance of the lightweight concrete are to be carefully evaluated. This paper presents some of the results obtained by means of laboratory testing as well in-situ testing. As part of the in-situ testing, the paper also reports on the practical evaluation of the ultra-lightweight material characteristics performed through the construction of a light weight concrete racing canoe. This allowed for the evaluation of the material performance characteristics and the establishment of acceptable work and application methods when constructing with this material.
\end{abstract}

\section{Introduction}

Specialized construction project applications may require a lightweight material that exhibits good all-round strength and durability characteristics. The need for structural elements having a low selfweight to accommodate large spans or weak supporting soil conditions may arise. In order to successfully and economically design such structures, there is a need for ultra lightweight but durable concrete material. In addition to the need for a lightweight concrete, another design requirement may be that of a durable thin concrete section. Such a material would suit applications such as façade cladding, internal walling, roof sheeting, flooring and even tunnel linings. Such applications may call for a non-structural material with acceptable strength properties but with a high degree of durability and 'toughness'. The development of suitable light weight concrete materials which are durable and stuff can ultimately lead to the optimisation of structural designs. Structures are often overdesigned to cope with unnecessary dead weight loadings of certain nonstructural elements. Such elements may simply be made of a 'suitable' class concrete simple because no acceptable light weight concrete is durable and tough enough. Although ordinary concrete products may fulfil their requirements perfectly, they often far exceed the ideal weight requirements. This may lead to higher costs and design constraints in other areas. It can thus be argued that the need for a modified concrete material which provides an optimum balance between strength, durability, toughness, low weight and cost efficiency is well defined. If this balance can be achieved, the possibility of using a modified light weight concrete as opposed to other construction materials such as timber, asbestos, glass, medium density fibre board (MDF) or polymer sheeting is exciting. A lightweight thin-film concrete material has the potential to become a desirable and competitive product and its application and performance characteristics can be enhanced through the addition of specialised aggregates, fibre reinforcement, concrete admixtures and various polymers. In this project, the concept of a lightweight material was taken a step further to that of an ultra-lightweight material suitable for thin-film concrete construction. 


\section{Lightweight Concrete}

Lightweight concrete or low density concrete is classed as concrete having a density of less than $2000 \mathrm{~kg} / \mathrm{m}^{3}$. Ultra-lightweight would indicate a density of below $1000 \mathrm{~kg} / \mathrm{m}^{3}$. Density of concrete is defined as the ratio of the mass of a given quantity of hardened concrete to its volume, in kilograms per cubic metre [1]. Lightweight concrete can be obtained in two ways, namely; through the use of lightweight aggregates and/or through the application of air entraining concrete admixtures or compounds. It is important to distinguish between structural and non-structural lightweight concrete. Structural lightweight concrete should ideally have a strength greater than $10 \mathrm{MPa}$ with a density ranging from $1200 \mathrm{~kg} / \mathrm{m}^{3}$ and $2000 \mathrm{~kg} / \mathrm{m}^{3}$ [2]. Non-structural lightweight concrete can be used for applications such as insulation, floor levelling or screeds and void filling. For applications such as insulation, lightweight aggregate concrete with compressive strengths of $0.7 \mathrm{MPa}$ is sufficient while for roof tiles and cladding panels, this strength requirement increases to between 0.7 to $3.5 \mathrm{MPa}$ [3]. Structural lightweight concrete is suitable for structural applications requiring lightweight concrete and for architectural finishes such as cladding [4].

Lightweight aggregates. Lightweight aggregates are aggregates that have a density of less than $2200 \mathrm{~kg} / \mathrm{m}^{3}$ [5]. Such aggregates are generally more expensive than the standard weight aggregates yet they allow for the production of a hardened concrete having a lower dry density. Lightweight aggregates may be naturally occurring, manufactured by crushing or milling of lowdensity rock, formed as by-products of other industrial processes and manufactured as synthetic aggregates. For this project, a naturally occurring volcanic glass (known as perlite) was selected as lightweight aggregate. In order for the volcanic glass to be incorporated in a lightweight concrete it must be pre-treated by crushing the volcanic glass followed by a thermal treatment which alters the grains into well-sealed glass beads having improved sphericity [6].

\section{Thin-film Concrete Sections}

Specialized civil engineering applications may require a material which can be produced in thin sections yet being very strong, tough and durable. Most thin concrete materials suffer from being brittle with a lack of durability and inadequate 'toughness'. This results in such materials not being considered for applications in situations which such properties are important. However, with the addition of reinforcement and polymeric modifiers, thin-film lightweight concrete composites may be produced with the characteristics to deform and to dissipate a significant amount of energy beyond the formation of the first cracks. With proper modification, thin-film concrete composites may display ductile tensile and flexural behaviour. The presence of micro-reinforcement in the cementitious matrix also helps to enhance the ultimate tensile strength of such composite [7]. Micro reinforcement within such thin-film concrete products is essential, without it the applications possibilities of such concrete is reduced drastically. Low diameter non-corrosive polymeric fibre reinforcement with good fibre-cement adhesion can be produced to ideally suit thin-film concrete applications. Such fibres are easy to work with and they have high tensile strength as well as durability properties.

Polymers. The purpose of adding polymers to the concrete matrix is to improve the characteristics of the fresh concrete (such as workability) and also to enhance the hardened properties such as flexural strength, modulus of elasticity and adhesive performance [8]. The incorporation of polymers into concrete may be in the form of polymer modified concrete (PMC), polymer impregnated concrete (PIC) or as polymer concrete (PC) [9]. For this project, the objective was to develop an ultra-lightweight concrete material using Portland cement as the main binder modified with a suitable polymer - thus a PMC application. The polymer modifiers selected for the development of the ultra-lightweight thin filmed material were; a commercially available SBR latex as well as a readily available acrylic polymer.

Fibre reinforcement. Asbestos fibre reinforced products were extremely popular in the recent past but owing to the inherent health risks its use is now restricted or even prohibited. This restriction has led to much research into alternative forms of reinforcement for thin concrete 
products. Fibres investigated were of natural or synthetic origin. In this project, the focus has been on commercially available synthetic fibres. These fibres may be used as either discrete fibres or as a continuous fibre mesh in the concrete matrix. Fibres benefit the brittle cementitious materials by enhancing the composite material's toughness, ductility and by interacting with stress induced micro-cracks [7]. Ductility is the ability of a material to be plastically deformed by elongation without fracture while toughness is the ability of a material to absorb energy before fracture [10]. The mechanism by which fibres improve the ductility of concrete is shown in Fig. 1; as the concrete face fractures the loads are transferred to the fibres exposed in this zone, provided that the bond between the anchored portion of the fibre and the concrete does not fail.

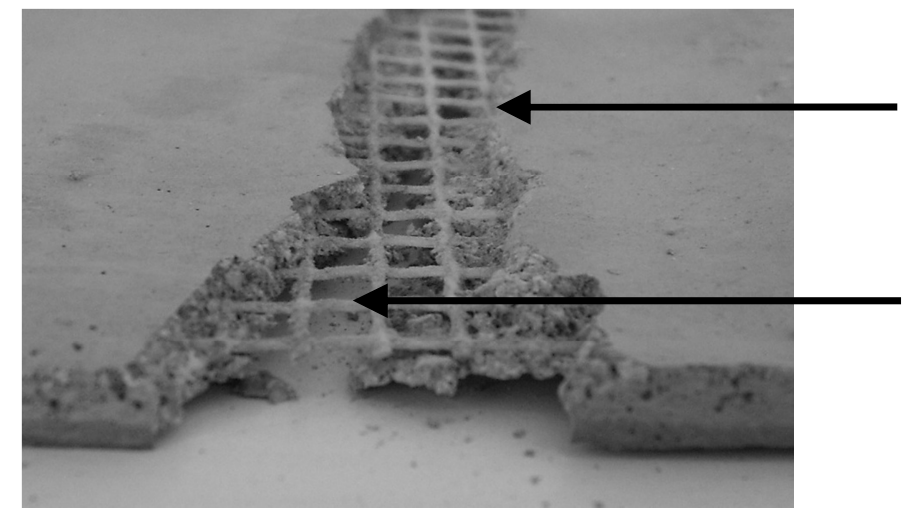

Crack in Mortar resulting in stress transfered to fibre mesh

Mesh Reinforcement bridges crack

Figure 1: Crack propagating through mortar retarded by fibre mesh

Continuous fibre mesh reinforcement. Fibre mesh is produced by the weaving of continuous strands of fibres together at $90^{\circ}$ angles forming a grid like pattern. The apertures in the mesh vary in size depending on weaving specifications but for use in concrete, these apertures must be greater than the size of the largest aggregate within the concrete. The factors affecting fibre mesh reinforcement are similar to those of discrete fibres apart from fibre dispersion related problems. Woven fibres do not have dispersion issues which make them more suitable for use in thin film applications and were thus selected for use in the development of the material for this project due to the absence of such dispersion problems. The fibre mesh selected was an alkali-resistant (AR) glass fibre mesh woven with $4 \mathrm{~mm}$ apertures.

\section{Experimental Procedures}

Trial mixes were prepared using a pre-treated perlite aggregate at a fixed ratio, a CEM IV $32.5 \mathrm{R}$ cement and potable water at two different w:c ratios and the two polymers at specified ratios. These trial mixes were then put through a testing program to determine their performance characteristics by evaluating the performance of both the concrete mortar as well as the characteristics of thin fibre reinforced sections using the various mortars. The trial mixes and their compositions are presented in Table 1.

Table 1: Trial mix compositions

\begin{tabular}{|l|l|l|l|l|}
\hline Sample ID & Perlite:cement & Water:cement & SBR latex polymer & Acrylic polymer \\
\hline Control CL & $3: 1$ & 0.69 & 0 & 0 \\
\hline P1NL* & $3: 1$ & 0.69 & 101 per $50 \mathrm{~kg}$ cement & 0 \\
\hline P1NR & $3: 1$ & 0.62 & 101 per $50 \mathrm{~kg}$ cement & 0 \\
\hline P2NL & $3: 1$ & 0.69 & 0 & $1: 2$ Acrylic:water \\
\hline P2NR & $3: 1$ & 0.62 & 0 & $1: 2$ Acrylic:water \\
\hline
\end{tabular}


* P1 = Polymer 1 (SBR Latex); P2 = Polymer 2 (Acrylic); $\mathrm{N}=$ Normal dosage; L = Low water:cement ratio; $\mathrm{R}=$ Reduced water:cement ratio

Testing program. The properties of the trial mixes in both the fresh and hardened state were determined. Fresh state properties measured were slump and flow parameters and workability when used in conjunction with AR fibre mesh reinforcement. Hardened state properties tested included compressive and flexural strength after 7 days of submersion curing at $26^{\circ} \mathrm{C}$. Fresh state properties were measured directly after the mixing was completed.

Tests conducted. The following tests were performed using the relevant standards as indicated:

- $\quad$ Slump test - SANS 5862-1 : 2006 [11]

- Flow test - SANS 5862-2 : 2006 [12]

- Compressive strength - SANS 5863 : 2006 [13]

- Flexural strength - SANS $5864: 2006$ [14]

- Density measurements

- Thin film sections $-250 \mathrm{~mm} \times 250 \mathrm{~mm} \times 5 \mathrm{~mm}$ test panels were made using the various trial mixes and reinforced with the AR glass fibre mesh. The thin film panels were subsequently constructed in three steps. Step 1: Placing a $2.5 \mathrm{~mm}$ layer of the trial mix mortar in a 250 X 250 mould; Step 2: Embedding the AR glass fibre mesh reinforcement in the wet mortar; Step 3: Cover the mesh with another $2.5 \mathrm{~mm}$ layer of the mortar. Fig. 2 shows the execution of step 2. During the production of these $5 \mathrm{~mm}$ thick test panels, the workability of the mortars and their compatibility with the AR glass fibre mesh reinforcement was monitored.

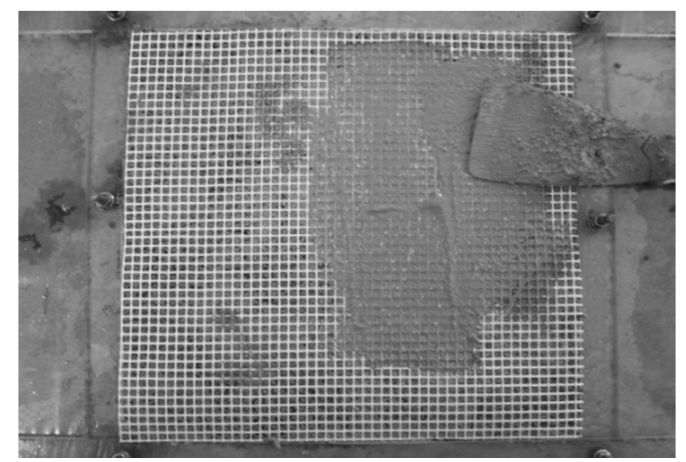

Figure 2: Step 3 of thin panel construction - placing alkali-resistant glass fibre mesh reinforcement

\section{Results and Discussion}

Density tests. Referring to Table 2 below, the densities of all the trial mixes ranged from just above $1000 \mathrm{~kg} / \mathrm{m}^{3}$ to $1073 \mathrm{~kg} / \mathrm{m}^{3}$. The addition of polymers into the trial mixes had a negligible effect on the densities of the concrete. The control mix, CL had a density of $1034 \mathrm{~kg} / \mathrm{m}^{3}$ which is very close to the densities of the other trial mixes; thus the density of the concrete is affected more by the lightweight aggregate and cement binder content rather than by the quantity or type of polymer addition.

Slump tests. The slump test for trial mixes CL, P2NL and P2NR gave a slump of $<5 \mathrm{~mm}$ indicating a failure of the slump test according to SANS 5862-1: 2006. The slump values of the trial mixes P1NL and P1NR are indicative of a very workable mix, however, according to Pankhurst (1993) [15] the slump test tends to underestimate the workability of a lightweight aggregate concrete. Because of this, the flow test may be more indicative of the workability of the lightweight trial mixes. 
Flow tests. The results of the flow test are presented in Table 2. Trial mixes CL, P2NL and P2NR showed severe segregation during the flow test. Although such mixes gave flow values, these values must be disregarded as the mixes lacked sufficient cohesion for the test to of any value. Fig. 3 (a) shows the typical lack of cohesion found in trial mixes CL, P2NL and P2NR while Fig. 3 (b) shows the results of the flow test for trial mixes P1NL and P1NR. These mixes had a more acceptable cohesive structure than the previous group of mixes.

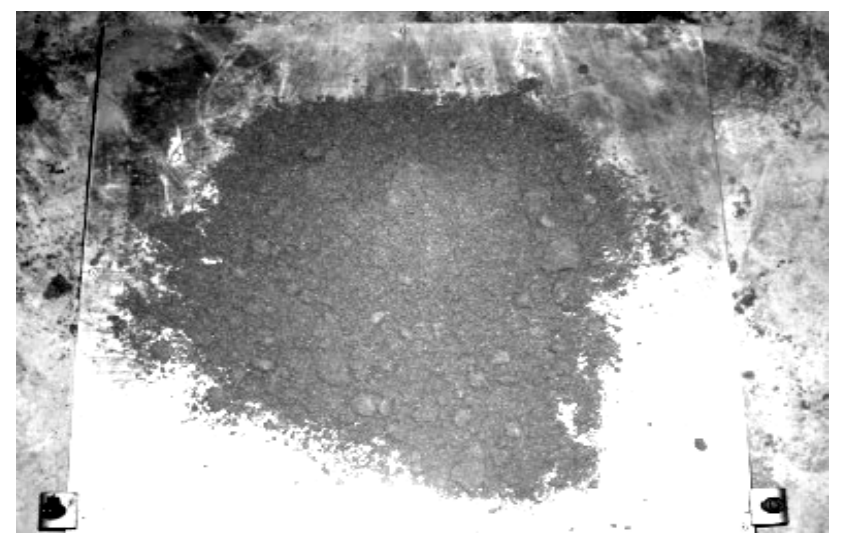

Figure 3: a) Typical segregation of CL, P2NL and

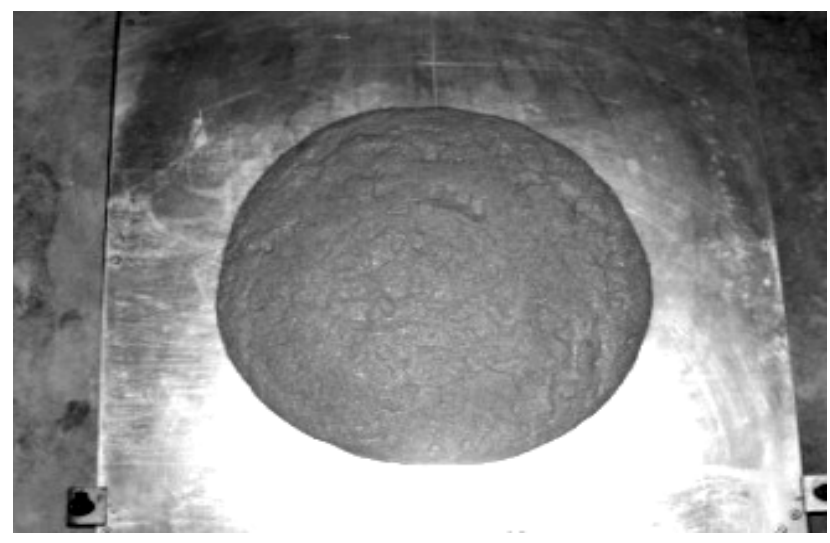

Figure 3: b) Flow test of P1NL cohesive mix P2NR low cohesive mixes

Table 2: Experimental results

\begin{tabular}{|l|l|l|l|l|l|}
\hline Sample ID & CL & P1NL & P1NR & P2NL & P2NR \\
\hline Density [kg/m³] & 1034 & 1001 & 1058 & 1073 & 1027 \\
\hline Slump [mm] & $<5$ & 143 & 113 & $<5$ & $<5$ \\
\hline Flow [mm] & 562.5 & 451.25 & 412.5 & 422.5 & 505 \\
\hline Type of flow & Segregation & Normal & Normal & Segregation & Segregation \\
\hline Compressive strength [MPa] & 1.1 & 5.1 & 5.8 & 1.43 & 1.37 \\
\hline Flexural strength [MPa] & 0.26 & 0.72 & 0.93 & 0.57 & 0.35 \\
\hline
\end{tabular}

Compressive strength. Trial mix P1NR offered the highest compressive strength of 5.8 MPa at 7day strength. The addition of SBR polymers has yielded an increase of more than $400 \%$ in compressive strength over that of the control mix CL. This is significant but we need to keep in mind that this is also a result from the change in water:cement ratio from 0.69 to 0.62. Mix P1NL having similar water:cement ratio as that of the control mix had an increase of more than $300 \%$ in its 7-day compressive strength.

Flexural strength. The flexural strength of the SBR modified specimen (P1NR) was the highest of all the trial mixes tested. An interesting observation from the load vs. deflection curves of the specimens, as shown in Fig. 4, is that specimens made from the acrylic modified mix (P2NR) was surpassed by the control mix (CL) with regards to yielding the greatest deflection. The $10 \%$ reduction in water: cement ratio between P1NL and P1NR led to a noticeable increase in the flexural strength and deflection achieved. This effect was however the opposite for P2NR which showed a lower flexural strength than P2NL. Fig. 4 plots the load-deflection curves obtained from the individual test specimens of each trial mix which exhibited the highest flexural performance. 


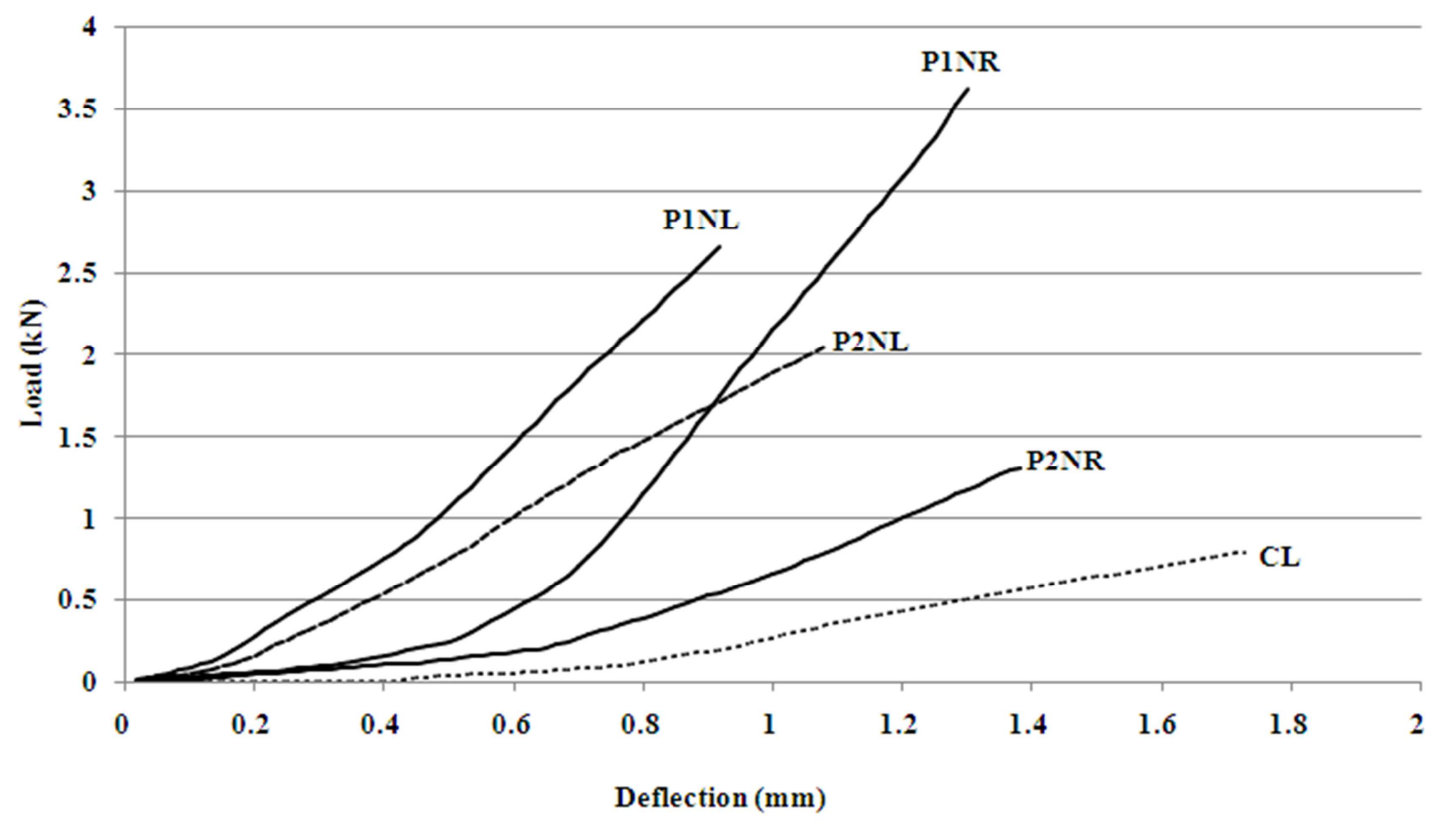

Figure 4: Flexural load vs. Deflection graphs for the various trial mixes.

Thin section panel results. The results of the thin section panel evaluation are presented Table 3 . Trial mixes P1NR and P1NL offered very similar workability and mesh bond characteristics. The difference in mesh concrete bond can be seen in Fig. 5 which compares the bond between the mesh and mix P1NL with that of the control mix CL. The trial mixes P1NR and P1Nl gave the best all round balance between workability and finish. As can be seen from Table 3, the trial mix P2NL may suit an extrusion process very well. This possibility was identified during the construction of the thin section panel specimens and will require further research. During the application of the mix mortar it was noticed that additional trowel pressure gave the mortar a 'putty' like appearance which also served to improve the surface finishes of the manufactured specimen.

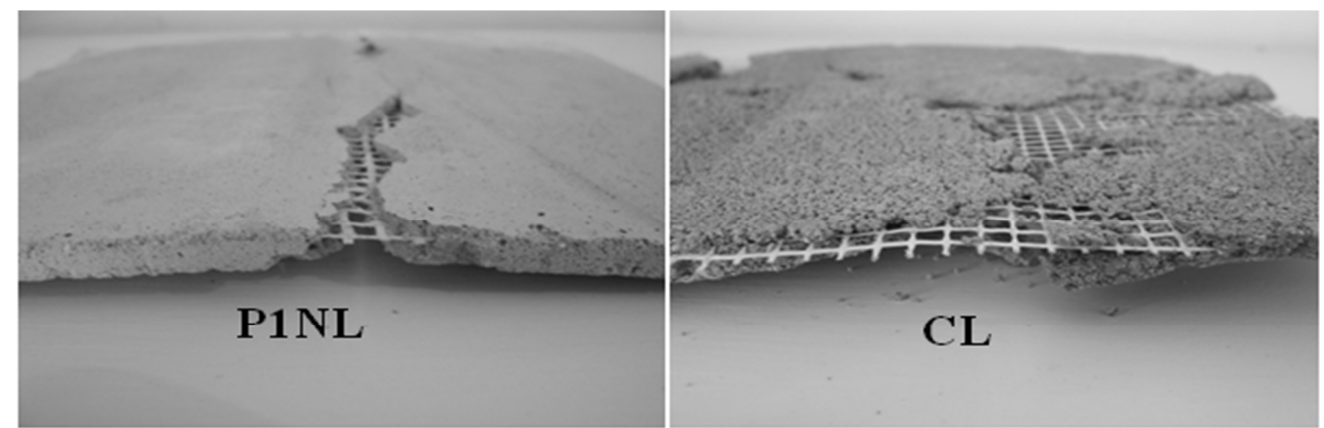

Figure 5: Concrete/mesh bond P1NL vs. CL

\section{Practical Evaluation}

As part of the in-situ testing, this ultra-lightweight material was used to construct a lightweight K2 racing canoe. Due to its superior strength characteristics, trial mix P1NR was selected for the construction of the racing canoe. During the construction of the canoe it was found that the lightweight concrete material used in conjunction with the alkali-resistant glass fibre mesh reinforcement becomes difficult to place in large sections. The mortar and mesh easily delaminated and it was found that the optimum thickness for such application was $15 \mathrm{~mm}$; this thickness prevented delamination and held the reinforcing firmly in place. The canoe was cast in two sections 
- namely a deck section and a hull section. Casting of the canoe deck is shown in Fig.6 a). These two sections were allowed to cure and were then demoulded and joined using an epoxy; the

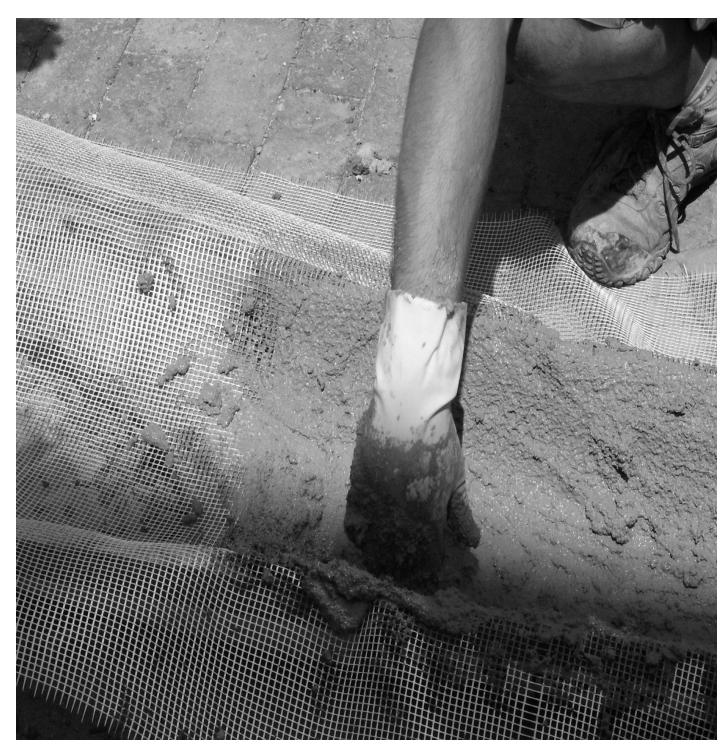

Figure 6: a) Casting of canoe deck

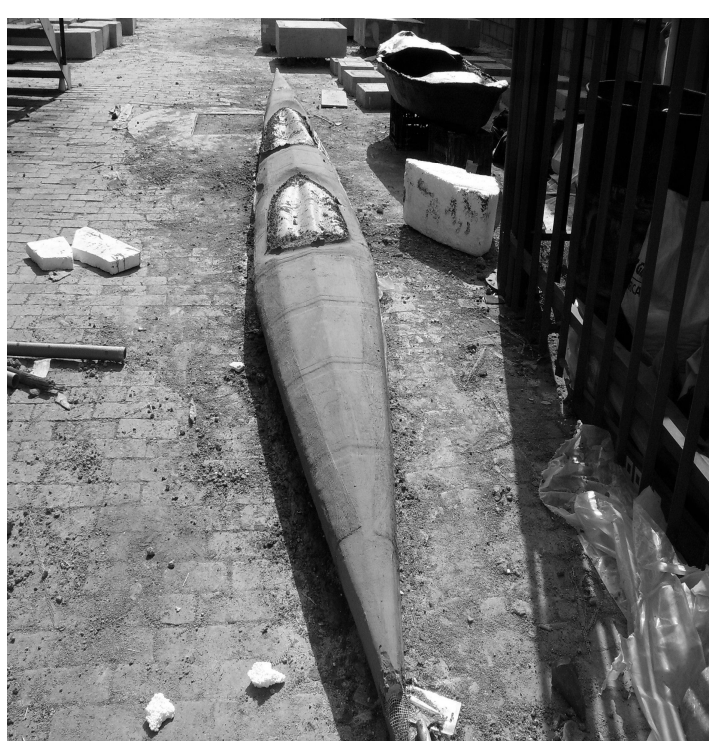

Figure 6: b) Complete canoe

completed canoe as shown in Fig. 6 b) had a total mass of only 50kg. The canoe was successfully tested in the water with one occupant and performed well; the concrete structure absorbed no water and suffered no ill effects from the harsh environment it was subjected to. Following repeated overturnings due to inexperienced boatmanship, the canoe was lifted whilst still full of water; this excessive loading condition resulted in the structural failure of the canoe hull. The material only failed after being subjected to loads far greater than intended and thus performed admirably. 
Table 3: Results and observations from thin section panel tests

\begin{tabular}{|c|c|c|}
\hline & Fresh state & Hardened state \\
\hline $\mathbf{C L}$ & $\begin{array}{l}\text { Very dry appearance } \\
\text { Difficulty in trowelling, material crumbles } \\
\text { Cannot obtain a smooth surface finish } \\
\text { Does not pass through mesh }\end{array}$ & $\begin{array}{l}\text { Difficulty demoulding; material } \\
\text { crumbles } \\
\text { Poor finish } \\
\text { Concrete delaminates from mesh }\end{array}$ \\
\hline P1NL & $\begin{array}{l}\text { Very fluid mix } \\
\text { Very good trowellability } \\
\text { Easy to impart good finish } \\
\text { Flows easily through mesh }\end{array}$ & $\begin{array}{l}\text { Easily demoulded } \\
\text { Very good finish } \\
\text { Good concrete/mesh bond } \\
\text { Good setting }\end{array}$ \\
\hline P1NR & $\begin{array}{l}\text { Very fluid mix } \\
\text { Very good trowellability } \\
\text { Easy to impart good finish. Similar to P1NL } \\
\text { Flows easily through mesh } \\
\text { To be used rapidly as trowellability reduces } \\
\text { within 30min }\end{array}$ & $\begin{array}{l}\text { Easily demoulded } \\
\text { Reasonable surface finish } \\
\text { Good concrete/mesh bond }\end{array}$ \\
\hline P2NL & $\begin{array}{l}\text { Good consistency, between dry and fluid } \\
\text { mix. May suit extrusion process of } \\
\text { application; obtains a putty like consistency } \\
\text { with increased trowelling pressure } \\
\text { Maintains good trowellability } \\
\text { Can impart reasonable finish with moderate } \\
\text { pressure }\end{array}$ & $\begin{array}{l}\text { Difficulty in demoulding } \\
\text { Good finish } \\
\text { Reasonable concrete/mesh bond } \\
\text { Slight retardation of setting }\end{array}$ \\
\hline P2NR & $\begin{array}{l}\text { Fair consistency, drier than with P2NL. } \\
\text { Would not suit extrusion process of } \\
\text { application; mix is possibly to dry. } \\
\text { Fair trowellability } \\
\text { Can impart a fair finish with heavy pressure } \\
\text { Flows through mesh with moderate effort; } \\
\text { not as effe } \\
\text { active as P2NL }\end{array}$ & $\begin{array}{l}\text { Must be demoulded with care } \\
\text { Reasonable surface finish; not as good } \\
\text { as P2NL } \\
\text { Fair concrete/mesh bond } \\
\text { Reasonable setting }\end{array}$ \\
\hline
\end{tabular}

\section{Conclusions}

When considering a cementitious mortar mix for use in the manufacturing of an ultra-lightweight thin film product, the addition of a suitable polymer modifier can enhance both the fresh and hardened properties of such lightweight material. The addition of styrene butadiene rubber latex (SBR) latex yielded the best overall results in terms of workability, formability, mouldability, flowability, compressive and flexural strengths. The improvements offered by the addition of the acrylic polymer were less impressive and the use of an acrylic modifier is thus not recommended for use in ultra-lightweight thin film products. It is also confirmed that small adjustments to the water:cement ratio alter the workability of such mixes and may be used to tweak mix designs to suit specific applications and uses. Thus with the addition of either a SBR latex or acrylic polymer and 
small adjustments to the water:cement ratio, it is possible to produce a high-performance lightweight thin film concrete material for different applications.

\section{References}

[1] South African Bureau of Standards. South African Standard 0100-1, The structural use of concrete, Part1: Design. South African National Bureau of Standards Pretoria, Gauteng, South Africa (2000).

[2] Day, K. W. Concrete Mix Design, Quality Control and Specification (3rd Edition ed.). Taylor \& Francis. London (2006).

[3] Pinto, R. C., and Hover, K. C. Frost and Scaling Resistance of High-Strength Concrete, Research and Development Bulletin RD122. In S. H. Kosmatka, \& B. Kerkhoff, Design and Control of Concrete Mixtures, EB001. Portland Cement association (PCA). Stokie, Illinois, United States of America (2003).

[4] Lafarge Industries South Africa (Pty) Ltd. (n.d.). Ultra Series. Ultra-lightweight Concrete.

[5] South African National Standards. SANS 1083:2006, Aggregates from natural sources Aggregates for concrete. South African National Standard. Standards South Africa. Pretoria, Gauteng, Republic of South Africa (2006).

[6] Information on http://www.pratley.com

[7] American Concrete Institute (ACI). Report on Thin Reinforced Cementitious Products. American Concrete Institute (ACI)(2009).

[8] Dimmig, A., and Kämpfer, W. 2001. Investigations of the sulphate resistance of polymermodified mortar (PCC). The Tenth International Congress on Polymers in Concrete and ICPIC/ICRI International Concrete Repair Workshop(2001).

[9] Miller, M. Polymers in Cementitious Materials. Rapra Technology. Shawbury, UK (2005).

[10] Paradis, F., and Morency, M. Optimizing a Concrete Canoe. (F. Paradis, Ed.) Concrete Canoe Magazine , 1 (1) (2006).

[11] South African National Standards. SANS 5862-1:2006, Concrete tests - consistency of freshly mixed concrete - slump test. South African National Standard. Standards South Africa. Pretoria, Gauteng, Republic of South Africa (2006).

[12] South African National Standards. SANS 5862-2:2006, Concrete tests- consistency of freshly mixed concrete - flow test. South African National Standard. Standards South Africa. Pretoria, Gauteng, Republic of South Africa (2006).

[13] South African National Standards. 2006. SANS 5863:2006, Concrete tests - Compressive strength of hardened concrete. South African National Standard. Standards South Africa. Pretoria, Gauteng, Republic of South Africa (2006).

[14] South African National Standards. SANS 5864:2006, Concrete tests - Flexural strength of hardened concrete. South African National Standard. Standards South Africa. Pretoria, Gauteng, Republic of South Africa (2006).

[15] Pankhurst, R. N. Construction. In J. L. Clarke (Ed.), Structural Lightweight Aggregate Concrete. Blackie Academic \& Professional. London (1993). 